Fecha de recepción

Fecha de evaluación:

Fecha de aprobación:

4 de diciembre de 2018

14 de diciembre de 2018

\section{Edwin Cruz Rodríguez ${ }^{*}$}

\title{
La recomposición del movimiento campesino en Colombia (2013-2016)
}

Para citar este artículo

Cruz, E. (2019). La recomposición del movimiento campesino en Colombia (2013-2016). Revista Vía luris ( $\left.\mathrm{n}^{\circ} 26\right)$, pp. 103-124.

\begin{abstract}
RESUMEN
Este artículo estudia la recomposición del movimiento campesino en Colombia. Tal reestructuración puede constatarse por la renovada capacidad para producir protestas de gran magnitud, estructuras de movilización unificadas de nivel nacional y marcos de acción colectiva capaces de articular diversos actores en torno a las causas del campesinado. Este fenómeno encuentra explicación tanto en la crisis del sector agrario como en un contexto político que amplía las oportunidades para la acción colectiva, principalmente por la apertura de la agenda pública consecuencia de las negociaciones de paz en La Habana. Para desarrollar este argumento, en primer lugar, se examina el ciclo de protesta entre 2013 y 2016. Seguidamente, se analizan las estructuras de movilización que sustentan las grandes movilizaciones. En tercer lugar, se estudian los principales marcos de acción colectiva que a ellas subyacen. Finalmente, se identifican algunas de las variables que pueden explicar la recomposición del movimiento campesino.
\end{abstract}

* Este trabajo corresponde a uno de los productos del proyecto de investigación: "Movilizaciones sociales en Colombia 2010-2016", el cual se adelanta en el grupo de investigación Teoría Política Contemporánea de la Universidad Nacional de Colombia-Instituto Unidad de Investigaciones Jurídico Sociales - Unijus. Periodo 2016-2017. Bogotá D.C., Colombia.

** Investigador. Politólogo, Candidato a doctor en Estudios Políticos. Integrante del Grupo de Investigación en Teoría Política Contemporánea de la Universidad Nacional de Colombia, Bogotá D.C., Colombia. ORCID https://orcid.org/0000-0001-8891-8796. Correo electrónico: ecruzr@unal.edu.co
DOI: https://doi.org/10.37511/viaiuris.n26a6

Esta obra está bajo una Licencia Creative Commons AtribuciónCompartirIgual 4.0 Internacional.
Palabras clave

Movimiento campesino, Colombia, protesta social, acción colectiva, cumbre agraria, paz. 


\title{
The recomposition of the peasant movement in Colombia (2013-2016)
}

\author{
Edwin Cruz Rodríguez
}

\begin{abstract}
This paper studies the recomposition of the peasant movement in Colombia. Such restructuring can be seen by the renewed ability to produce large-scale protests, mobilizing structures unified national and collective action frames able to articulate various actors around the causes of the peasantry. This phenomenon is explained both the crisis in the agricultural sector and a political context that expands opportunities for collective action, mainly by opening up the public agenda because of the peace negotiations in Havana. To develop this argument, first examines the cycle of protest between 2013 and 2016. Subsequently, mobilization structures that support the great mobilizations are analyzed. Third, the main frames of collective action that underlie them are studied. Finally, we identify some of the variables that can explain the recompositing of the peasant movement.
\end{abstract}

\section{Keywords}

Peasant movement, Colombia, social protest, collective action, summit land, peace. 


\title{
A recomposição do movimento camponês na Colômbia (2013-2016)
}

\author{
Edwin Cruz Rodríguez
}

\section{RESUMO}

Este artigo estuda a recomposição do movimento camponês na Colômbia. Essa reestruturação pode ser visto pela renovada capacidade para produzir grandes protestos, mobilizando as estruturas de ação nacional e coletiva unificada quadros capazes de articular diversos atores em torno das causas do campesinato. Este fenômeno é explicado tanto a crise no sector agrícola e em um contexto político que amplia as oportunidades para a ação coletiva, principalmente, abrindo a agenda pública por causa das negociações de paz em Havana. Para desenvolver este argumento, primeiro ciclo de protesto entre 2013 e 2016. Posteriormente, as estruturas de mobilização que suportam as grandes mobilizações são analisados sob revisão. Em terceiro lugar, os principais quadros de acção colectiva que lhes estão subjacentes são estudados. Finalmente, eles identificam algumas das variáveis que podem explicar a recomposição do movimento camponês.

Palavras-chave

Movimento camponês, Colômbia, protesto social, ação coletiva, cimeira agrária, paz. 


\title{
La recomposition du \\ mouvement paysan en Colombie (2013-2016)
}

\author{
Edwin Cruz Rodríguez
}

\section{RÉSUMÉ}

Cet article étudie la recomposition du mouvement paysan en Colombie. Une telle restructuration se traduit par la capacité renouvelée de produire des manifestations de grande envergure, mobilisant des structures unifiées dans des cadres d'action nationale et collective capables d'articuler divers acteurs autour des causes de la paysannerie. Ce phénomène s'explique à la fois par la crise du secteur agricole et par le contexte politique qui élargit les possibilités d'action collective, notamment en ouvrant l'agenda public à la suite des négociations de paix à La Havane. Pour développer cet argument, examine d'abord le cycle de protestation de 2013 à 2016. Ensuite, les structures de mobilisation qui soutiennent les grandes mobilisations sont analysées. Troisièmement, les principaux cadres d'action collective qui les sous-tendent sont étudiés. Enfin, nous identifions certaines des variables pouvant expliquer la recomposition du mouvement paysan.

\section{Mots-clés}




\section{INTRODUCCIÓN}

En los últimos años la sociedad colombiana ha sido testigo de grandes protestas del campesinado, únicamente comparables con las que desarrolló la Asociación Nacional de Usuarios Campesinos (Anuc), a principios de los años setenta, cuando consiguió articular distintas vertientes regionales y tendencias políticas del campesinado alrededor de su estructura organizativa, marcos de acción colectiva unificados y repertorios de acción como la toma de tierras (Múnera, 1998). En 2013 hubo tres movilizaciones que afectaron la vida nacional: el paro nacional cafetero en febrero-marzo, el paro en el Catatumbo en junio-julio, y el paro nacional agrario en agostoseptiembre. En marzo y abril de 2014 hubo otro paro nacional agrario motivado, según los voceros campesinos, por los incumplimientos del Gobierno con los compromisos adquiridos el año anterior. En esta movilización se consolidó la Cumbre Agraria, Campesina, Étnica y Popular, una plataforma que articula las principales organizaciones de movimientos sociales en el país, que en las negociaciones para terminar el paro fue reconocida por el Gobierno como contraparte legítima. Sin embargo, tras 19 meses de negociaciones, en mayo de 2016, la Cumbre convocó una Minga Agraria, Campesina, Étnica y Popular, nuevamente motivada por el incumplimiento. Este ciclo de protestas contrasta con el declive de las movilizaciones campesinas desde principios de los años dos mil, constatado por Prada (2003) y Suhner (2002), a causa de las adversas consecuencias de la agudización del conflicto armado y la represión. ¿Cuáles son los factores que explican este resurgimiento del movimiento campesino?

Este trabajo estudia la recomposición del movimiento campesino mediante las categorías desarrolladas en la "agenda clásica" del estudio de los movimientos sociales (McAdam, Tarrow y Tilly, 2005; McAdam, McCarthy y Zald, 1999; Tarrow, 1997). Este enfoque sintetiza las principales variables de las que se han ocupado las teorías de la acción colectiva para explicar el origen y desarrollo de los movimientos, sin reducir las explicaciones a una sola variable, ya se trate de las tensiones estructurales (Smelser, 1995), la racionalidad estratégica de los actores (Olson, 1992) o la construcción de la identidad (Touraine, 1987; Melucci, 1999). Así, articula los factores estructurales y subjetivos que explican las dinámicas de acción colectiva. La categoría de estructura de oportunidades políticas (EOP) designa los elementos contextuales que constriñen o coadyuvan a la acción colectiva, mientras que los conceptos de estructuras de movilización y marcos de acción colectiva refieren las redes de relaciones sociales que se activan y los procesos de construcción de sentido, respectivamente.

La recomposición del movimiento campesino puede constatarse por la renovada capacidad para producir protestas de gran magnitud, estructuras de movilización unificadas de nivel nacional y marcos de acción colectiva capaces de articular diversos actores en torno a las causas del campesinado. Este fenómeno encuentra explicación tanto en la crisis del sector agrario como en un contexto político que amplía las oportunidades para la acción colectiva, principalmente por la apertura de la agenda pública con las negociaciones de paz en La Habana.

Para desarrollar este argumento, en primer lugar, se examina el ciclo de protesta entre 2013 y 2016. Seguidamente, se analizan las estructuras de movilización que sustentan las grandes movilizaciones. En tercer lugar, se estudian los principales marcos de acción colectiva que a ellas subyacen. Finalmente, se identifican algunas variables para explicar la recomposición del movimiento campesino.

\section{METODOLOGÍA}

Este estudio siguió un enfoque metodológico cualitativo de tipo hermenéutico, en el cual la interpretación del movimiento social está orientada por distintas categorías analíticas propias de este campo de estudios, tal como se detalla en cada una de las partes del documento. Los datos para este análisis provienen de fuentes secundarias, estudios históricos, análisis coyunturales del movimiento campesino, seguimiento de prensa, y fuentes primarias, principalmente comunicados y otros textos de las organizaciones del movimiento campesino. Estos datos fueron ingresados a una matriz que permitió relacionar las categorías de análisis (protesta, estructura de oportunidad política, estructuras de movilización y marcos de acción colectiva), y ordenar toda la información en un marco cronológico. Todo lo anterior con el objetivo de identificar las relaciones entre la recomposición del movimiento, tomada como variable dependiente, y los datos asociados a las distintas categorías analíticas, tomadas como variables independientes, y formular hipótesis explicativas. 


\section{RESULTADOS Y DISCUSIÓN}

\section{El repunte de la protesta}

Como sostiene Godás (2007), a diferencia de la protesta, el movimiento social se caracteriza por un cierto grado de organización y de perdurabilidad. Las protestas constituyen solo uno de los repertorios de acción posibles y no siempre son agenciadas por un movimiento social. Sin embargo, uno de los indicadores de la recomposición del movimiento campesino es su capacidad para generar grandes protestas. El paro cafetero, el paro en el Catatumbo y el paro nacional agrario en 2013, el paro agrario de 2014 y la Minga Campesina, Étnica y Popular en 2016, permiten apreciar la magnitud del fenómeno, que ha interpelado al Gobierno Nacional, afectado virtualmente todo el país y articulado los distintos sectores populares del campo con otros actores organizados y pobladores urbanos.

Entre el 25 de febrero y el 8 de marzo de 2013, tuvo lugar la protesta más importante en la historia del gremio cafetero, el Paro Nacional Cafetero. Aunque las demandas que sustentarían el paro se plantearon desde principios de 2012, la institucionalidad del gremio, en cabeza de la Federación Nacional de Cafeteros (FNC), y el Gobierno no las atendieron. Los caficultores, por su parte, emprendieron un proceso organizativo que les permitió articularse en acciones colectivas con objetivos de mediano plazo. En febrero de 2012, en Pereira, tuvo lugar una reunión de dirigentes cafeteros de seis departamentos, quienes hicieron un diagnóstico de crisis del sector, manifestaron su oposición al alza de la contribución cafetera y decidieron formar el Movimiento por la Defensa y Dignidad de los Cafeteros Colombianos (Dignidad Cafetera), para afrontar la crisis.

El 3 de junio, en Riosucio (Caldas), se realizó el Encuentro Regional Cafetero del Occidente, donde se construyó el pliego de peticiones del movimiento, con ocho puntos referidos a la fijación de un precio remunerativo estable e independiente del precio internacional, políticas de fomento a la producción cafetera nacional, no al incremento de impuestos a los caficultores, control al precio de agroinsumos, una auditoría al Fondo Nacional del Café y un diagnóstico del funcionamiento de las instituciones del gremio, solucionar el problema de deuda de los caficultores, incentivar programas gratuitos de control de plagas y el rechazo al TLC con EE.UU. por permitir la importación de cafés procesados.
Andando la protesta, se sumó un noveno punto: el rechazo a la minería en zonas cafeteras. Ante la falta de atención del Gobierno, el 27 de octubre se convocó el paro.

El paro inició el 25 de febrero, a los tres días la prensa calculó en 140.000 las personas movilizadas en todo el país y resaltó el desabastecimiento de alimentos a causa de los bloqueos, en varias ciudades y departamentos (El Espectador, 2013a). Después de varios intentos, el 7 de marzo las partes llegaron a un acuerdo. Se fijó un subsidio de 145000 pesos por carga, denominado "Protección al Ingreso de los Caficultores". Respecto al precio, se estableció un techo de $\$ 700000$ por carga y un piso de $\$ 480000$ (El Espectador, 2013b). A fin de discutir los demás ítems del pliego de peticiones se crearon comisiones de trabajo. Aunque el paro fue un duro golpe a la FNC, su gerente no renunció. Tampoco se tocó el problema que para los caficultores era de fondo: el libre comercio y el modelo de acumulación basado en la minería.

En junio y julio de 2013 la región del Catatumbo fue afectada durante 53 días por un paro campesino, que movilizó más de diez mil personas y mantuvo bloqueada buena parte del país. Su desencadenante fue la erradicación forzada de cultivos de uso ilícito, a cargo de las Fuerzas Armadas (FF.AA.), sin implementar programas de economía alternativa. Sin embargo, allí confluyeron problemas estructurales de esta región estratégica sistemáticamente abandonada por el Estado y rica en recursos naturales cuya explotación ha producido varios ciclos de violencia. El campesinado reivindicó el reconocimiento de una zona de reserva campesina (ZRC) como parte de la solución de sus problemáticas, pero fue vetada por el ministerio de Defensa, pese a cumplir con todos los trámites, por considerar que era un ardid de las FARC para tener ventajas estratégicas.

El principal repertorio de acción fueron los bloqueos sobre la vía Tibú-Cúcuta. Se produjeron enfrentamientos entre la fuerza pública y los campesinos, que dejaron 4 manifestantes muertos. El Gobierno planteaba que no negociaría si no se levantaban los bloqueos. Por su parte, los voceros campesinos presentaron un pliego de exigencias que incluía mantener la metodología de la Mesa de Interlocución y Acuerdo (MIA), espacio de negociación con el Gobierno desde 2009, con 200 líderes campesinos y seis voceros. Ante la represión, las sucesivas negativas y las dilaciones del Gobierno, el 29 de 
julio los manifestantes retiraron el bloqueo en Campo Dos, uno de los cinco puntos, como gesto de buena voluntad y presentaron una propuesta de desbloqueo para retomar el diálogo con el Gobierno. El presidente Santos accedió a discutir el pliego de exigencias, incluyendo la creación de la ZRC. En la madrugada del 3 de agosto se produce el levantamiento de los bloqueos y el 9 de agosto se alcanza un acuerdo entre la Asociación Campesina del Catatumbo (Ascamcat) y el Gobierno, según el cual la MIA se reuniría tres días a la semana durante cuatro semanas para negociar.

En medio de la protesta en el Catatumbo se anunció un paro nacional agrario, que se desarrolló entre el 19 de agosto y el 12 de septiembre y constituye la protesta agraria más importante de las últimas décadas. La mayor parte del territorio nacional se vio afectada por bloqueos, mítines, marchas y cacerolazos. Según estimaciones de los convocantes, participaron más de 200000 personas (El Espectador, 2013c). La principal razón para protestar era el incumplimiento del Gobierno con los acuerdos producto de anteriores protestas, pero las organizaciones campesinas, Dignidad Agropecuaria, la Mesa de Interlocución y Acuerdo (MIA) y el Coordinador Nacional Agrario (CNA) empezaron el paro divididas y produjeron tres pliegos. Las reivindicaciones comprendían una política agraria para resolver los problemas estructurales del sector, reducir los precios de los insumos agrícolas, detener las importaciones de productos nacionales, suspender los tratados de libre comercio, condonar las deudas de los productores, establecer precios de sustentación e impedir la extranjerización de la propiedad territorial, entre otras.

El primer día las movilizaciones no fueron muy nutridas debido a la división entre los convocantes, aunque hubo acciones colectivas en 30 de los 32 departamentos del país (Prensa Rural, 2013). La manifestación daría un giro radical tras las declaraciones del presidente Santos, quien para aminorar la importancia de la protesta, declaró: "Ese tal paro nacional agrario no existe" (El Espectador, 2013d), puesto que generó un sentimiento de indignación. Además, se empezaron a conocer videos en las redes sociales virtuales de policías agrediendo a los campesinos, robando comida y víveres, destruyendo campamentos e ingresando a sus viviendas sin orden judicial (El Espectador, 2013e). El rechazo a este comportamiento motivó los "cacerolazos" en las principales ciudades convocados por redes sociales virtuales, que posicionaron la ruana como símbolo de solidaridad con el campesinado. Ante el fortalecimiento del paro, el Gobierno cedió a negociar en medio de los bloqueos con Dignidad Agropecuaria, en una mesa de negociación que se instalaría el 27 de agosto.

Las negociaciones dejaban por fuera a la MIA y al CNA, por lo que para el 29 de agosto se promovió una movilización en la que se produjeron grandes enfrentamientos con la Policía en ciudades como Bogotá y Medellín. El alcalde de Bogotá, Gustavo Petro, decretó toque de queda en las localidades de Bosa, Suba y Engativá, en cada una de las cuales hubo un asesinato. Al final de la jornada, quedaron 5 muertos y más de 200 heridos (El Tiempo, 2013a). Al día siguiente el ministro de Defensa, Juan Carlos Pinzón, acusó a las FARC de estar detrás de esas acciones (El Tiempo, 2013b). El presidente Santos ordenó la militarización de varias ciudades, entre ellas Bogotá (Semana, 2013a).

Pese a la fuerza que tomó la protesta, la estrategia gubernamental de negociar en mesas fragmentadas rindió frutos y paulatinamente se empezaron a sellar acuerdos para levantar los bloqueos e iniciar negociaciones en las distintas regiones movilizadas. El 5 de septiembre se llegó a un acuerdo con Dignidad Agropecuaria para no aplicar la resolución 970 de 2010 sobre semillas certificadas y trabajar el tema en una mesa. No obstante, no hubo acuerdo sobre la renegociación de los TLC Con EE.UU. y la UE. Finalmente, el 7 de septiembre, se alcanzó el acuerdo con la MIA. El Gobierno se comprometía a crear salvaguardias para la importación de productos agropecuarios de países con los que Colombia tuviese acuerdos comerciales y constituir una comisión de alto nivel para negociar su pliego de peticiones.

Por otra parte, el Gobierno nombró a un empresario de palma de aceite, Rubén Darío Lizarralde, como ministro de Agricultura y el 12 de septiembre realizó el Pacto Agrario con los gremios. Los voceros de la MIA se negaron a asistir por considerar que no reflejaba los intereses de los campesinos sino los de los empresarios. Para la misma fecha desarrollaron la Gran Cumbre Agraria y Popular, con las demás organizaciones campesinas. Entre el 12 de septiembre y el 15 de marzo de 2014 se realizaron 22 "precumbres" en las diferentes regiones del país para construir un pliego unificado (MIA, 2015). Del 15 al 17 de marzo se realizó la Cumbre Agraria, Étnica y Popular, en Bogotá, que terminó con una marcha de cerca de 30000 personas, la presentación del 
pliego unificado y la convocatoria a un paro nacional agrario el 28 de abril, debido al incumplimiento del Gobierno (Semana, 2016). Esta protesta se realizó en época preelectoral, entre el 28 de abril y el 9 de mayo. Luego de varios intentos de negociación, el Gobierno accedió a la conformación de la Mesa Única de Participación y Concertación, que significó el reconocimiento político de la Cumbre Agraria.

Sin embargo, tras 19 meses de negociaciones los incumplimientos del Gobierno motivaron otra gran protesta. Entre el 30 de marzo y el 12 de junio de 2016 se desarrolló la Minga Agraria, Campesina, Étnica y Popular, en la que participaron cerca de 100000 personas. De acuerdo con los manifestantes, el Gobierno no cumplió sus compromisos, pero no escatimó esfuerzos para tramitar con rapidez la Ley de Zonas de Interés de Desarrollo Rural, Económico y Social, que permite la concentración de grandes extensiones de tierra por empresarios. El Gobierno intentó reducir el alcance de la protesta implementando una dura represión en contra de los bloqueos y tratando de fraccionar a los manifestantes con mesas de negociación regionales. En los días anteriores a la movilización, la atención se enfocó en la región del Catatumbo, debido a la retención de los periodistas Diego D'Pablos, Carlos Melo y Salud Hernández por parte del ELN. No obstante, pronto la atención se desplazó hacia el suroccidente del país.

Frente a las complicaciones que supone el bloqueo de la vía Panamericana, el desabastecimiento de parte de los departamentos de Cauca y Nariño y la imposibilidad de circular hacia Ecuador, el Gobierno priorizó la negociación con los pueblos indígenas y optó por presionar su desbloqueo. Andando la protesta, el ministro de Agricultura, Aurelio Iragorri, afirmó que había alcanzado un acuerdo para desbloquear la vía Panamericana, pero la Cumbre lo desmintió. Las declaraciones contradictorias del ministro se enmarcaban en la estrategia de fragmentar el movimiento y conseguir acuerdos parciales en regiones como Chocó, Arauca, Casanare, Huila, Nariño, Putumayo y Catatumbo. Sin embargo, ante la amenaza del Gobierno de desbloquear la vía Panamericana por la fuerza y como un gesto de buena voluntad para entablar el diálogo, la Cumbre realizó un desbloqueo humanitario el 10 de junio, por 36 horas, para favorecer el inicio de los diálogos y se acordó reinstalar la mesa de negociación en Santander de Quilichao.
Al día siguiente se llegó a un acuerdo que incluía garantías para la movilización con un monitoreo de la Oficina del Alto Comisionado de las Naciones Unidas para los Derechos Humanos y la Defensoría del Pueblo, avances para el reconocimiento de territorios campesinos agroalimentarios (TCA) y la exploración de la viabilidad jurídica de las zonas de reserva campesina (ZRC), e incluir la categoría de "campesino" en el censo nacional como parte del reconocimiento político del campesinado. El Gobierno se comprometió a combatir el paramilitarismo, proteger los líderes sociales y proponer un mecanismo de participación efectiva de los movimientos sociales en la construcción de paz. Hubo avances en el reconocimiento de las guardias indígenas como agentes autónomos de control social y territorial, en la construcción de una política pública minero-energética, que incluía la revisión de todos los otorgamientos de licencias y concesiones ambientales y minero-energéticas para corroborar su legalidad, la realización de un diálogo nacional minero-energético y una ruta para abordar la relación campo-ciudad. Sin embargo, el principal logro fue el reconocimiento político de la Cumbre Agraria por parte del Gobierno.

\section{Los procesos organizativos}

Un segundo indicador de la recomposición del movimiento campesino es la renovada capacidad para crear estructuras de movilización. En el enfoque del proceso político estas son concebidas como "canales colectivos tanto formales como informales, a través de los cuales la gente puede movilizarse e implicarse en la acción colectiva" (McAdam, McCarthy \& Zald, 1999, p. 25). Como sostiene McCarthy (1999), existen organizaciones del movimiento social (OMS), más o menos formales cuyo fin es promover la movilización para alcanzar los fines del movimiento, pero también otras organizaciones sociales y políticas con fines diversos y redes de relaciones sociales de la vida cotidiana, que se articulan a las movilizaciones en determinadas coyunturas. El ciclo de protesta campesina desde 2013 ha conllevado también el esfuerzo por construir la unidad organizativa en el marco de la Cumbre Agraria, Campesina, Étnica y Popular.

Siguiendo el estudio de Suhner (2002), las más recientes experiencias de unidad organizativa a nivel nacional se encuentran en el Consejo Nacional de Organizaciones Agrarias e Indígenas de Colombia 
(Conaic) y el Consejo Nacional Campesino, que entre 1999 y 2003 desarrolló un intenso proceso alrededor del proyecto de ley de reforma agraria que pretendía modificar sustancialmente la Ley 160 de 1994. La tabla 1 resume los principales procesos de unidad organizativa a nivel nacional.

Tabla 1. Principales procesos organizativos de unidad campesina a nivel nacional

\begin{tabular}{|c|c|c|}
\hline Estructura unitaria & $\begin{array}{c}\text { Organizaciones } \\
\text { integrantes }\end{array}$ & Fechas \\
\hline $\begin{array}{l}\text { Mesa Nacional } \\
\text { de Unidad } \\
\text { Agraria }\end{array}$ & $\begin{array}{l}\text { Anmucic, Fensua- } \\
\text { gro, ANUC-UR, CNA, } \\
\text { Fenacoa, Apeme- } \\
\text { café, Fanal, ACC } \\
\text { Sintraincoder, Aso- } \\
\text { gras, Federación } \\
\text { Comunal, ADUC } \\
\text { Cundinamarca } \\
\text { y el Comité de } \\
\text { Interlocución Mar- } \\
\text { cados Campesinos }\end{array}$ & $\begin{array}{l}2006 \text { hasta } \\
\text { hoy }\end{array}$ \\
\hline $\begin{array}{l}\text { Coordinadora } \\
\text { Nacional Agraria } \\
\text { y Popular, Conap }\end{array}$ & $\begin{array}{l}\text { Fensuagro, } \\
\text { Fenacoa, } \\
\text { Sintraincoder, } \\
\text { ACVC, Asociación } \\
\text { Campesina del } \\
\text { Catatumbo } \\
\text { y algunas } \\
\text { organizaciones } \\
\text { regionales. }\end{array}$ & $\begin{array}{l}2007 \text { hasta } \\
\text { hoy }\end{array}$ \\
\hline $\begin{array}{l}\text { Convergencia } \\
\text { Nacional, } \\
\text { Campesina Negra } \\
\text { e Indígena } \\
\mathrm{CNI}\end{array}$ & $\begin{array}{l}\text { Anmucic, } \\
\text { Fensuagro, ANUC- } \\
\text { UR, CNA, Sintradín, } \\
\text { PCN, ONIC, } \\
\text { Fenacoa. }\end{array}$ & $\begin{array}{l}2003 \text { hasta } \\
2006 \text {. Se di- } \\
\text { solvió en } 2006 \\
\text { para darle } \\
\text { paso a la Mesa } \\
\text { Nacional de } \\
\text { Unidad Agraria }\end{array}$ \\
\hline Vía Campesina & $\begin{array}{l}\text { Fenacoa, CNA, } \\
\text { Fensuagro, ANUC- } \\
\text { UR, ACVC. }\end{array}$ & $\begin{array}{l}1996 \text { hasta } \\
\text { hoy }\end{array}$ \\
\hline $\begin{array}{l}\text { Consejo Nacional } \\
\text { Campesino } \\
\text { CNC }\end{array}$ & $\begin{array}{l}\text { Anmucic, } \\
\text { Fensuagro, ANUC- } \\
\text { UR, CNA, Sintradín, } \\
\text { ONIC, Fenacoa, } \\
\text { Fanal, Festracol, } \\
\text { ACC, Acbra y la } \\
\text { CND. }\end{array}$ & $\begin{array}{l}1999 \text { hasta } \\
2003\end{array}$ \\
\hline $\begin{array}{l}\text { Consejo Nacional } \\
\text { de Organiza- } \\
\text { ciones Agrarias } \\
\text { e Indígenas de } \\
\text { Colombia, Conaic }\end{array}$ & $\begin{array}{l}\text { Fensuagro,Sintradín, } \\
\text { ONIC, Fanal, ACC, } \\
\text { Festracol, Fenacoa, } \\
\text { Anmucic, ANUC-UR. }\end{array}$ & $\begin{array}{l}1991 \text { hasta } \\
1998\end{array}$ \\
\hline
\end{tabular}

Fuente: PNUD (2012, p. 99).

Como anteriormente se argumentó, hoy en día el movimiento se articula en la Cumbre Agraria. En ella convergen dos grandes tendencias organizativas, la Mesa Agropecuaria y Popular de Interlocución y Acuerdo (MIA) y el Coordinador Nacional Agrario (CNA). Por su parte, Dignidad Agropecuaria, si bien permanece independiente, se ha articulado en acciones específicas. Como arguye Dorado (2013), mientras esta última representa pequeños y medianos productores de café, papa, leche y cebolla, entre otros, los campesinos representados por el CNA y la MIA provienen de zonas de reciente colonización, que han sido fuertemente golpeadas por el conflicto armado interno, cuyas urgencias están enfocadas en garantizar la propiedad de la tierra, por eso abanderan las zonas de reserva campesina o los territorios campesinos agroalimentarios, infraestructura, servicios públicos y alternativas económicas para la erradicación de cultivos de uso ilícito.

La MIA es una iniciativa de Marcha Patriótica, plataforma de diversos movimientos sociales rurales y urbanos que nació en 2013 y en la que participan, entre otras, la Federación Nacional Sindical Agropecuaria (Fensuagro) y la Asociación Nacional de Zonas de Reserva Campesina (Anzorc). La figura de la mesa de interlocución nació en el marco del proceso de construcción de la zona de reserva campesina del Catatumbo, que se propone como una alternativa de ordenamiento territorial para resolver diversos problemas de esta región, encabezado por la Asociación Campesina del Catatumbo (Ascamcat). Allí se formó una MIA desde 2009, con el fin de entablar negociaciones con el Gobierno. La figura operó durante las protestas de junio y julio de 2013, de ahí que fuese retomada en el paro agrario de agosto y septiembre de ese año, a nivel nacional y en mesas regionales (MIA, 2015).

El origen del CNA se remonta hasta el I Foro Nacional Agrario, que se realizó en Bogotá en 1997, en donde convergieron varios procesos organizativos de distintas regiones como el Comité de Integración Social del Catatumbo (CISCA), la Asociación Campesina de Antioquia (ACA), el Comité de Integración del Macizo Colombiano (CIMA), el Comité de Integración del Galeras (CIGA) y la Federación Agraria y Minera del sur de Bolívar (Fedeagrobismol). El CNA fue fundamental para la creación del Congreso de los Pueblos, en 2010, una plataforma de movimientos sociales análoga a la Marcha Patriótica, cuyos antecedentes se hallan en la Minga de Resistencia Social de 2008, como lo evidencian Salcedo, Pinzón y Duarte (2013). En consecuencia, y tal como ha documentado el CINEP (2013), su base, originalmente de pequeños 
campesinos, se ha diversificado, ampliándose hacia indígenas organizados en la ONIC, afrodescendientes en el Proceso de Comunidades Negras, pequeños mineros e incluso algunos sectores urbanos.

Finalmente, Dignidad Agropecuaria reúne varias plataformas organizativas regionales inspiradas en Dignidad Cafetera, organización con arraigo en el Eje Cafetero que lideró el paro de febrero y marzo de 2013. Inicialmente Dignidad Cafetera se formó sobre la marcha para afrontar demandas muy específicas, sintetizadas en el pliego de peticiones y orientadas a responder a la crisis del sector cafetero. En ese trayecto consiguió desarrollar cuatro encuentros nacionales donde se planificaron las agendas y estrategias de movilización. Algunos de sus dirigentes participaron en la organización independiente Unidad Cafetera o han ocupado cargos de elección popular, pero también hay líderes ajenos al mundo político (El Tiempo, 2013c).

Esta experiencia inspiró a pequeños productores de Nariño y Boyacá, protagónicos en el paro nacional agrario de 2013. Según César Pachón, uno de los líderes inicialmente de Dignidad Papera y luego de Dignidad Agropecuaria, en su entrevista con Duzán (2014), los cultivadores de papa de Boyacá realizaron dos paros, el 16 de noviembre de 2011 y el 7 de mayo de 2013. Ese día Pachón participó en una audiencia en el Congreso, en la que recibió el apoyo de los caficultores. Dado que en ese momento representaba la "Dignidad Papera" y la "Dignidad Cebollera", y ante la falta de resultados en las negociaciones con el Gobierno les propuso formar la Dignidad Agropecuaria.

Dignidad Agropecuaria representa intereses de medianos productores agrícolas de Cundinamarca, Boyacá, Nariño, Santander y Norte de Santander, cultivadores de papa, cebolla, arroz y productores de leche. Por esa razón, su pliego de peticiones se enfoca en regulaciones de precios, importaciones e insumos. En contraste con el pliego del CNA o el de la MIA, no reivindica una reforma agraria, alternativas económicas para la sustitución de cultivos ilícitos, ni el reconocimiento formal de territorios campesinos agroalimentarios o zonas de reserva campesina. Sus preocupaciones no están enfocadas en los problemas de la tierra y el territorio, propios de campesinos pobres, víctimas del despojo violento, a menudo dedicados al cultivo de coca y asentados en zonas de reciente colonización.
Estos dos grandes procesos organizativos convergen en la principal estructura de movilización en el actual movimiento campesino, la Cumbre Agraria, Étnica y Popular, una articulación de 13 organizaciones cuyo origen se remonta al paro agrario de agosto de 2013. Como anteriormente se afirmó, el 12 de septiembre de ese año se produjo una primera reunión o Cumbre Agraria entre las organizaciones comprometidas en el paro, con el objetivo de hacer contrapeso a la reunión paralela que sostenía el Gobierno con los gremios del sector en el marco del Pacto Agrario. Según el documento de la MIA (2015), entre esa fecha y marzo de 2014 se realizaron 22 "precumbres" en las diferentes regiones del país con el fin de construir un pliego unificado de los sectores populares rurales, campesinos, indígenas y afrodescendientes. Entre el 15 y el 17 de marzo se reunió finalmente la Cumbre Agraria, Campesina, Étnica y Popular.

Las 13 organizaciones que la componen son muy diversas. Como se ha mencionado, existen dos plataformas nacionales de movimientos sociales, la Marcha Patriótica, fundada en 2013, y el Congreso de los Pueblos, cuyo origen se remonta hasta 2010. Ambas reúnen organizaciones sociales de distintas regiones, urbanas, rurales y de otros sectores. También está presente la Coalición de Movimientos y Organizaciones Sociales de Colombia (Comosoc). Las demás son organizaciones que pertenecen a alguna de estas plataformas. Así pues, la Cumbre Agraria se erige como representante de los actores populares del campo colombiano.

Ahora bien, en la práctica no todas las organizaciones asumen el mismo compromiso con la movilización. Por ejemplo, la Minga de 2016 fue promovida principalmente por el Congreso de los Pueblos y la ONIC. La Asociación Campesina del Catatumbo (Ascamcat), que pertenece a la Marcha Patriótica y a Anzorc y organizó el paro regional de junio y julio de 2013, manifestó su respaldo a la protesta pero decidió no participar por distintas razones, desde la difícil situación económica por la que pasaban sus asociados debido al fenómeno del niño, hasta el hecho de haber priorizado la marcha por la paz a realizarse el 15 de julio (Prensa Rural, 2016a). Así mismo, Dignidad Agropecuaria, cuyas acciones fueron fundamentales en el paro agrario de 2013, anunció que tampoco participaría, pues estaba enfocada en un referendo por el campo que radicó el 12 de mayo en la Registraduría y que se propone 
reformar los artículos 64, 65 y 100 de la Constitución para renegociar los tratados de libre comercio, insertando, como en su momento informó Vélez (2016), un mandato para que el Estado garantice la soberanía alimentaria e impida la extranjerización de la propiedad territorial.

Ahora bien, aunque el impulso de la movilización corrió por cuenta de estas grandes estructuras organizativas, tanto en las áreas urbanas como en las rurales implicó otro tipo de redes de relaciones y formas asociativas formales e informales. El Paro Nacional Cafetero fue posible gracias al aprovechamiento de la infraestructura organizativa formal e informal del sector, así como de la formación del Movimiento por la Defensa y Dignidad Cafetera, como instancia de coordinación que supo movilizar las redes de relaciones cotidianas del campesinado cafetero para orientarlas a la protesta. El sector cafetero dispone de una importante infraestructura gremial, lo que se traduce en importantes aprendizajes y acumulados en cuanto a acción colectiva. En muchos casos los comités municipales y departamentales de la FNC jugaron un papel destacado en la articulación de las bases de la protesta. Otro elemento importante son los altos niveles de democratización tanto de la organización gremial como en la forma como se han organizado durante más de un siglo los procesos de producción en las zonas cafeteras. De acuerdo con Arango (2013), existen 538000 productores de café de menos de cinco hectáreas, que constituyen el $96 \%$ del total de productores, asentados en 631 municipios.

A nivel local, el paro cafetero corrió a cargo de las organizaciones de apoyo y las comunidades en general. Siguiendo el reporte de Gutiérrez (2003), los lugares de protesta funcionaron con mecanismos de autogestión, los participantes debían aportar comida y determinados trabajos. Si bien la organización básica consistió en comisiones espontáneas para atender distintas labores (comida, seguridad, aseo, derechos humanos, salud), esa espontaneidad se levantaba sobre fuertes vínculos sociales, fraternales y familiares. Las formas de organización reprodujeron los lazos de vecindad producidos en la vereda, fundamentales a la hora de garantizar tareas como el transporte, la cocina y la seguridad.

En el mismo sentido, en departamentos como Boyacá y Nariño, que muchas veces son concebidos como "conservadores", hubo una amplia participación del campesinado en el paro nacional agrario de
2013. En rigor, en estas regiones no se movilizaron organizaciones de movimientos sociales propiamente dichas, sino comunidades, en el sentido en que Zibechi (2006) le confiere a este concepto, es decir, las relaciones sociales familiares, de vecindad, de compadrazgo, que sustentan la vida cotidiana vincularon a las personas a la acción colectiva. Las comunidades tenían incentivos para movilizarse por el hecho de que poblaciones enteras, no solo los pequeños y medianos productores agropecuarios sino también los comerciantes, los transportadores y los proveedores de otros servicios, dependen de la economía agropecuaria, lo cual hizo que se vincularan a las demandas de los productores. Pero no solo las relaciones cara a cara contribuyeron a la movilización. Como anteriormente se mencionó, el uso de las redes sociales virtuales desempeñó un papel fundamental para que la protesta se extendiera con los cacerolazos hacia las ciudades.

\section{Los marcos de acción colectiva}

Un tercer elemento que permite cotejar la recomposición del movimiento campesino es la creación de marcos de acción colectiva. De acuerdo con Snow y Benford (1992), estos corresponden a procesos de construcción de sentido, esquemas de interpretación de la realidad y de los problemas sociales relevantes, que construyen quienes participan en un movimiento social. Para MacAdam, McCarthy y Zald (1999, p. 27), el objetivo de un marco es "forjar formas compartidas de considerar el mundo y a sí mismos que legitimen y muevan a la acción colectiva". Por consiguiente, como resaltan los estudios de Rivas (1998) y Zald (1999), no se trata de significados dados, sino de concepciones elaboradas estratégicamente con el fin de articular diversos actores al objetivo político del movimiento social.

Entre el paro agrario de 2013 y la Minga de 2016 existe un proceso de enmarcamiento que puede comprenderse como el tránsito desde varias demandas de sectores particulares del campesinado hacia un marco unitario presente en el pliego de peticiones construido por la Cumbre Agraria. Los antecedentes de este proceso de enmarcamiento son el Mandato del Congreso Nacional Agrario de 2003, en el contexto de la campaña que varias organizaciones sociales desarrollaron "Por el derecho a la tierra", y el Manifiesto por la Tierra y la Paz, producto del Encuentro Nacional de Comunidades Campesinas, Afrodescendientes e Indígenas, realizado en Barrancabermeja en agosto de 2011 
(PNUD, 2012). Ambos documentos dan cuenta de un tránsito en los marcos de acción colectiva del movimiento campesino, que en general apuntan hacia una ampliación de la agenda de reivindicaciones. Hoy se asume que resolver los problemas del campesinado pasa por una transformación del modelo de desarrollo económico, basado en la minería a gran escala y los agronegocios en beneficio del gran capital y de las empresas transnacionales. Así, la agenda de reivindicaciones va más allá de la demanda de tierra y territorio o de reforma agraria, para abarcar una diversidad de políticas estatales relacionadas con el reconocimiento efectivo del campesinado como sujeto de derechos y como actor político. De hecho, como argumenta el Cinep (2013), la identidad del campesinado ha sufrido una transformación, puesto que sus atributos dejan de estar referidos predominantemente a la posición de estos agentes en la estructura productiva para proyectarse hacia la diversidad característica de las poblaciones populares rurales, los pueblos indígenas, las comunidades afrodescendientes y las mujeres, entre otros.

En el paro agrario de 2013 no hubo en estricto sentido un marco de acción colectiva unificado, puesto que no se consiguió acordar un solo pliego de demandas entre los actores convocantes. No obstante, los tres pliegos permiten aproximarse al sentido que enmarcó la protesta social, el tipo de problemas sociales que la suscitaron y sus responsables. En todos los casos hay una identidad compartida como "campesinos" y el principal adversario de sus propuestas es el Gobierno, que sistemáticamente incumple los acuerdos con las comunidades, no reconoce al campesino como un actor político legítimo y ha adoptado políticas agrarias contrarias a los intereses de los pequeños y medianos productores pero favorables a las grandes empresas de agronegocios.

Sin embargo, entre los tres documentos hay diferencias notables en relación con los problemas que pretenden resolver. El pliego de Dignidad Agropecuaria hace énfasis en el cumplimiento de acuerdos de protestas anteriores, para Nasaacin (2013) la reducción de los precios de los insumos y la protección de la producción nacional frente a las importaciones propiciadas por los tratados de libre comercio y el contrabando, y la extensión del subsidio cafetero. El pliego de la MIA plantea una agenda de problemas más amplia, aunque comprende los anteriores, puesto que reclama soluciones como políticas agrarias estructurales, el acceso a la propiedad de la tierra y la reivindicación de figuras como las zonas de reserva campesina, e incluso garantizar los derechos políticos de los campesinos y otros actores sociales y políticos (MIA, 2013). Finalmente, el pliego del CNA comparte varias de las reivindicaciones con el de la MIA, aunque hace un énfasis en las demandas de los pueblos indígenas y afros, como el reconocimiento de autonomía y territorio para la construcción de vida digna (Congreso de los Pueblos, 2013).

El marco de acción colectiva de la Cumbre Agraria, que actualmente unifica las distintas corrientes del movimiento, está sintetizado en el pliego unitario de peticiones construido entre 2013 y 2014 . Tal pliego reúne en sus 8 puntos un conjunto de demandas que constituyen la ruta para una reforma rural integral, entre las que se encuentran el reconocimiento de las figuras territoriales del campesinado y las comunidades afro e indígenas, el reconocimiento del campesinado como sujeto de derechos, la participación política efectiva, la reforma agraria, soluciones para el problema minero-energético, la construcción de paz y la relación campo-ciudad, entre otras (Prensa Rural, 2016b).

Este conjunto de peticiones tiene la virtud de articular las demandas de distintos actores del campo colombiano. Por consiguiente, la identidad colectiva que trata de construirse comprende una diversidad de identidades agrarias, de campesinos sin tierra que habitan en regiones de colonización, de cultivadores de coca, de pequeños y medianos productores y de trabajadores del campo en general, así como de poblaciones indígenas y afrodescendientes. La articulación de esta diversidad de actores es posible, por una parte, al interpelar lo rural pero también lo popular. De ahí el nombre de Cumbre Agraria, Campesina, Étnica y Popular. Pero, además, porque en el discurso del movimiento todos los actores que lo conforman tienen un adversario en común, el Gobierno, sus políticas agrarias y el modelo de desarrollo económico.

Durante la Minga de 2016 se enfatizaron los incumplimientos del Gobierno en comparación con su eficacia cuando se trata de sacar avante políticas agrarias favorables a los empresarios, pero al mismo tiempo se ubicaron las demandas del movimiento en los problemas más amplios del modelo de desarrollo económico y de la construcción de paz. Así, en la carta que dirigieron al Presidente el 30 de noviembre de 2015 afirmaban: 
Mientras las comunidades agrarias demandamos una reforma agraria integral que supere la desigualdad histórica en la propiedad de la tierra, y como elemento fundamental para superar el conflicto social y armado, el Gobierno sigue empeñado en sacar adelante la iniciativa legislativa que pretende crear las "Zonas de Interés de Desarrollo Rural y Económico (Zidres)", figura que permite que los baldíos de la nación pasen a manos no sólo de campesinos desposeídos, como lo contempla la Ley 160 de 1994, sino también y principalmente a grandes inversionistas agroindustriales. Mientras las comunidades agrarias no logramos luego de dos años de negociación acceder a nuestros derechos territoriales, los grandes inversionistas en menos de un año han logrado la atención prioritaria con todas las prerrogativas de su gobierno. (Congreso de los Pueblos, 2015, p. 5)

Como puede verse, el reclamo de la Cumbre realizaba una crítica tanto a la política agraria de Santos como al modelo económico en su totalidad. De hecho, sus reivindicaciones estaban inextricablemente vinculadas a la construcción de la paz. Por esa razón en la convocatoria a la Minga, el "Llamamiento al pueblo colombiano" del 22 de mayo, vinculaban la discusión sobre el modelo económico, que el Gobierno se había negado a negociar en La Habana pero que se apuntalaba en el Plan Nacional de Desarrollo, con la protesta:

El gobierno de Juan Manuel Santos y sus predecesores han sido enfáticos al expresar públicamente que el modelo de desarrollo del país no es negociable y aunque la ciudadanía se ha manifestado en contra del mismo, el Estado colombiano sigue sin escuchar $u$ ofrecer alternativas sostenibles para dar solución de fondo y de manera estructural a la crisis económica, ambiental y social que se agudiza en todo el territorio colombiano. Hoy nuestro llamado es a enfrentar las nocivas políticas extractivistas que ponen en riesgo los bienes naturales, la soberanía nacional y la pervivencia física y cultural de las comunidades rurales y del conjunto del pueblo colombiano... Diversos sectores sociales (víctimas, ambientales, transportadores, sindicales, mujeres, educativos, urbanos y rurales, entre otros) venimos oponiéndonos a las políticas gubernamentales que responden a los Tratados de Libre Comercio y se expresan en el Plan Nacional de Desarrollo (PND) que pone en venta los recursos estratégicos de la nación, las empresas públicas, los bienes energéticos, el agua y distribuye de manera inequitativa la tierra, aumentando los beneficios en favor de unos pocos y excluyendo a millones de ciudadanos, campesinos, indígenas y negros de sus legítimos derechos. (Congreso de los Pueblos, 2016, p. 5)

Por otra parte, tanto el incumplimiento del Gobierno como sus estrategias para reducir la importancia de la movilización despertaron un sentimiento de indignación similar al que se desató cuando, en agosto de 2013, en medio del paro agrario, el presidente Santos declaró "el tal paro agrario no existe". En ese momento, tal afirmación se tomó como una falta de respeto al campesinado, que contribuyó a la afirmación de su identidad incluso entre pobladores de las ciudades, quienes desarrollaron cacerolazos y erigieron la ruana como símbolo de su solidaridad con los campesinos. Algo similar ocurrió durante la Minga, especialmente cuando el presidente Santos nombró la región del Catatumbo como "el Bronx de Colombia". En realidad, lejos de ser un lapsus, esta afirmación reproduce los imaginarios que las élites políticas tienen sobre regiones periféricas de reciente colonización, como el Catatumbo.

Ramírez (2001) develó parte de ese imaginario al estudiar las protestas cocaleras de 1996 en el Putumayo, otra región de colonización vista por el Gobierno central como bárbara y selvática, cuyos habitantes se perciben como ingobernables y proclives al crimen. De ahí que en el comunicado que produjo la Cumbre para denunciar la represión y el tratamiento militar que se le estaba dando a la protesta afirmaran: "Somos actores civiles y políticos legítimos y no se nos puede equiparar a un grupo armado. Y las comparaciones desafortunadas de zonas campesinas como el Catatumbo con el Bronx, solo es válida (sic) en tanto las situaciones de extrema pobreza son tratadas militarmente" (Desde Abajo, $2016 a$, p. 7). Con esto no solo ponían de presente su indignación, sino que reclamaban un tratamiento distinto al militar para los problemas de esta región.

Ahora bien, a partir del diagnóstico de los problemas del agro, del modelo económico, y de la identidad de campesino, la Cumbre Agraria creó un marco de acción colectiva que interpeló al pueblo colombiano en su totalidad. De ahí su "Llamamiento al pueblo", en el cual sostenían:

Reiteramos el llamado amplio a todas las personas y comunidades del campo y la ciudad, para que 
expresemos en un solo sentir nuestra voz de esperanza por un cambio de rumbo en el país, que garantice el buen vivir de las presentes y futuras generaciones. Pongámonos la ruana, el sombrero, el bastón de mando y salgamos a caminar la palabra en calles y carreteras, campos y ciudades, para manifestar nuestro compromiso en defensa del agua, el alimento, a las semillas nativas, a la naturaleza y la identidad cultural. Nuestra lucha es por la vida. Camine con nosotros. (Congreso de los Pueblos, 2016, pp. 10-11)

En fin, más allá de las reivindicaciones puntuales y de los acuerdos incumplidos por el Gobierno, en este marco de acción colectiva el sentido de la protesta estuvo constituido por un cambio radical en el modelo económico que empieza por una reforma agraria. Así se enunciaba en un apartado del "Llamamiento al pueblo" titulado "Por el buen vivir, una reforma agraria estructural". El primer concepto ha sido retomado por sectores indígenas, afrodescendientes y campesinos de las experiencias de otros movimientos sociales en América Latina, en particular en Bolivia y Ecuador, donde al modelo neoliberal, que privilegia el crecimiento económico en desmedro de las necesidades humanas y el deterioro del medio ambiente, se opuso el "buen vivir", como un horizonte de sentido que a partir de una crítica del paradigma del desarrollo persigue la armonía entre los seres humanos y entre ellos y la naturaleza:

Reiteramos nuestro apoyo al proceso de diálogos de paz con las FARC y con el ELN, pues estamos convencidos de la salida negociada al conflicto armado; pero de la misma manera, consideramos que se requieren soluciones concertadas al conflicto social, político y económico, necesarias para una paz con justicia social y ambiental. En consecuencia, y como una justa e histórica reivindicación, reclamamos del gobierno nacional que se garantice la participación activa, vinculante y decisoria de las comunidades para diseñar y construir la Reforma Agraria Integral que redistribuya y democratice la propiedad de la tierra y reoriente el modelo de desarrollo económico en armonía con la naturaleza y la diversidad cultural. (Congreso de los Pueblos, 2016, pp. 8-9)

En fin, entre 2013 y 2016 hay una recomposición del movimiento campesino en Colombia, que se expresa en un inédito ciclo de protestas de gran magnitud, en procesos de unidad a nivel nacional y en la creación de marcos de acción colectiva capaces de interpelar tanto a los actores populares agrarios como a diversos sectores sociales. ¿Cómo explicar este fenómeno?

\section{Hacia una explicación del fenómeno}

Los actores comprometidos en el excepcional ciclo de protesta campesina tienden a explicar su origen y desarrollo por dos razones: la crisis agraria y el incumplimiento del Gobierno. La crisis socioeconómica del sector rural afecta a pequeños y medianos productores debido a los altos precios de los insumos, la competencia con productos importados producto de los tratados de libre comercio y el contrabando, las dificultades para acceder al crédito y a la propiedad de la tierra, entre otros (Duzán, 2014). Así mismo, el incumplimiento del Gobierno se ha interpretado como menosprecio y ha generado indignación. Estos son factores necesarios pero no suficientes para explicar la protesta y la recomposición del movimiento campesino. En otras circunstancias ha habido crisis agraria, incluso muchos de los problemas del sector son estructurales, y aun así no se había presentado un ciclo de protesta de esta magnitud. Además, como han señalado diversos estudios (Ramírez, 2001; Suhner, 2002; Cinep, 2013), el incumplimiento de los acuerdos por el Gobierno ha sido una constante en la historia del país, particularmente con el movimiento campesino, y no siempre ha generado protestas de envergadura.

Por lo tanto, es necesario identificar las variables que explican la recomposición del movimiento campesino. En el enfoque de los procesos políticos estas variables se conciben en el marco de la estructura de oportunidades políticas (EOP), que designa los factores del contexto político que incentivan o constriñen la acción colectiva (Tarrow, 1997), tanto a nivel de la estructura institucional como por cambios en las relaciones de poder (McAdam, McCarthy y Zald, 1999). El concepto fue criticado por su amplitud, pues al comprender cualquier dimensión contextual corría el riesgo de perder capacidad explicativa (Gamson y Meyer, 1999). Por eso, autores como McAdam (1999) se esforzaron en precisar las variables pertinentes: el grado de apertura del sistema político, la estabilidad en las coaliciones, la presencia o ausencia de aliados para el movimiento social y la capacidad de represión estatal. Otra crítica señala que no solamente las oportunidades políticas inciden en el origen y desarrollo 
de las movilizaciones, sino también factores sociales y culturales. Así, Ruch (1999) resalta la necesidad de dar cuenta del contexto socioeconómico más amplio en el que tiene lugar la acción colectiva.

En esta perspectiva, la crisis agraria es un elemento central, aunque no suficiente, para explicar la recomposición del movimiento. De acuerdo con Suhner (2002), la crisis agraria hunde sus raíces en el cambio de modelo económico a principios de los noventa, cuando de un sector protegido por el Estado se viró hacia un esquema abierto al mercado, que llevó a una tasa negativa de crecimiento en el PIB del sector de -2.0 para 1992 y una marcada disminución de cultivos de algodón, arroz, cebada, maíz, papa, tabaco, soya, trigo y hortalizas, por el aumento en un $700 \%$ de las importaciones, especialmente de cereales. Como consecuencia, la balanza comercial agraria entró en déficit, lo que aumentó los costos de producción nacionales. Siguiendo el análisis del Cinep (2013), la crisis suscitó varias protestas campesinas, en demanda de una política agraria para contrarrestar la baja en los precios de sus productos debido a la importación y el contrabando, el aumento de costos financieros por la eliminación de los subsidios a las tasas de interés, y la reorganización de las instituciones estatales del sector.

Salcedo, Pinzón y Duarte (2013) y el Cinep (2013) muestran que varias de estas demandas reaparecieron en el paro de 2013, debido a la agudización de la situación tras la firma de tratados de libre comercio que pusieron a los productores nacionales en mayor desventaja, la ausencia de una política agraria, de institucionalidad estatal para el agro y las consecuencias ambientales negativas de la política minero-energética del Gobierno Santos. La pequeña producción campesina, algunas veces organizada en consejos comunitarios (comunidades negras), resguardos indígenas o zonas de reserva campesina, ha venido cediendo terreno, en la mayoría de ocasiones por vía de la violencia y la instrumentalización de las instituciones del Estado en función de intereses particulares, frente a la agroindustria y la gran minería, según lo ha documentado Molano (2013).

El paro cafetero y el paro en el Catatumbo permiten aproximarse a las manifestaciones regionales de dicha crisis. El sector cafetero se ha sumido en una crisis producto de la apertura económica que empezó con el fin del Pacto de Cuotas entre los países productores, tras operar por 29 años, a causa de la presión de EE.UU., en junio 1989. Esa situación se ha visto desbordada desde 2012 por la baja producción, en comparación con Brasil y Vietnam, la baja cotización internacional, las importaciones de grano para atender la demanda nacional y la revaluación del peso producto de la "enfermedad holandesa", debida al ingreso de divisas en inversiones de megaminería. Los caficultores empezaron a producir a pérdida, se generaron grandes problemas de desempleo, hambre y desaceleración económica en las regiones productoras, donde el café funciona como dinamizador de otras actividades.

El Catatumbo es una región de colonización, en donde la agudización de la guerra llevó a una complicada crisis humanitaria, que se adicionó a otros problemas de esta región, como la disputa por el control de los recursos naturales y los cultivos de uso ilícito, cuyo origen deriva del abandono estatal. Entre 1998 y 2005 el paramilitarismo hizo presencia con el Bloque Catatumbo de las Autodefensas Unidas de Colombia, que en ese período asesinó cerca de 11200 personas, desplazó 19000 familias, realizó 60 masacres y dejó 600 personas desaparecidas. Según los estudios de Molano (2013) y el PNUD (2014), la guerra destrozó el tejido social, llevó a un desplazamiento de 77495 personas y transformó la estructura de la propiedad y los usos del suelo, generando grandes concentraciones ganaderas y de palma africana, de la mano del programa Plante y las "alianzas productivas" con grandes empresarios agroindustriales promovidas por el Gobierno Pastrana (1998-2002). La respuesta del Gobierno ha sido un tratamiento militar de los problemas; por ejemplo, en el momento de la protesta promovía la erradicación manual de cultivos de uso ilícito, una de las pocas alternativas de subsistencia del campesinado, en el marco del Plan Consolidación, a cargo de las FF.AA. Como sugiere Restrepo (2013), las demandas del campesinado en Catatumbo evidencian el histórico descuido estatal con esa región, pues se presentaron desde el paro del nororiente en 1987, y se han reiterado desde esa fecha.

Por otra parte, el contexto político se caracteriza por una ampliación de las oportunidades para la protesta bajo el Gobierno Santos, si se compara con el anterior, que comprende tres grandes conjuntos de factores: primero, un ciclo de movilizaciones que abre oportunidades al mostrar la vulnerabilidad del Gobierno; segundo, las negociaciones de paz amplían la agenda pública permitiendo el posicionamiento 
de demandas sociales no tramitadas y, tercero, el apoyo de diversos actores contrarresta el ascenso de la represión.

La recomposición del movimiento campesino se inscribe en un ciclo ascendente de protestas que inicia con el paro universitario de octubre de 2011 (Cruz, 2014). Según el Cinep (2014), en 2013 hubo 1027 acciones de protesta, lo que constituye el pico más elevado comparado con los registros anuales que esta entidad registra desde 1975. Así, es probable que los actores sociales opten por la movilización para realizar sus reivindicaciones al percibir que el Gobierno es vulnerable frente a este tipo de acción, de acuerdo con la tendencia descrita por Wallerstein (2008).

Aunque el presidente Santos llegó al Gobierno como abanderado de la causa de la seguridad democrática y se esperaba un estilo similar al de su antecesor, Álvaro Uribe (2002-2010), desde el primer momento le imprimió una dinámica distinta, que empezó por la recomposición de las relaciones diplomáticas con los países vecinos y el inicio de negociaciones de paz con las FARC, en agosto de 2012. En consecuencia, hubo una apertura de la agenda pública que fue aprovechada por actores sociales diversos para posicionar sus reivindicaciones, que se acompañó con el reconocimiento del derecho a la protesta y la oposición política, lejos de la condena que de ella se hizo en el anterior Gobierno (López, 2014). Pero también hubo una división entre las élites políticas representadas por Santos y Uribe, lo que se traduciría en oportunidades políticas para los movimientos sociales.

Una variable imprescindible de la EOP es el nivel de represión de la protesta. McAdam (1999) sugiere que cuando disminuye la represión es más probable que emerjan ciclos de protesta. Empero, esta hipótesis es matizada en nuestro caso, puesto que tanto la criminalización como la represión de la protesta se ha mantenido y ha tendido a crecer proporcionalmente a la movilización.

La criminalización de la protesta se hizo efectiva con la Ley 1453 de 2011, que en su artículo 353 literal a, penaliza la obstrucción de vías públicas, principal repertorio de acción de los campesinos. Por ejemplo, el 6 de marzo de 2013, en el paro cafetero, se anunció la apertura de investigación a 70 personas por delitos de perturbación del orden público y obstrucción de vías, ya había 30 judicializadas (Diario del Huila, 2013). Antes de iniciar el paro agrario ese mismo año, el 16 de agosto, el mismo presidente Santos dio la orden de no permitir bloqueos (El Tiempo, 2013d). Pero la criminalización también se expresa en el discurso contrainsurgente que relaciona toda protesta como una expresión del "enemigo interno". Así, en prácticamente todas las protestas se encuentran declaraciones de altos funcionarios que acusan a los campesinos por estar manipulados por las guerrillas. En el paro cafetero, el 26 de febrero de 2013, el ministro de Agricultura, Juan Camilo Restrepo, declaró que las FARC estaban involucradas (El Espectador, 2013f). Frente a la protesta en el Catatumbo, funcionarios civiles y militares afirmaron que la protesta estaba manipulada por las FARC para forzar el reconocimiento de la ZRC. El 19 de junio, el mismo presidente Santos afirmó que las marchas estaban infiltradas por las FARC (El Tiempo, 2013e). Durante el paro agrario, el 29 de agosto de 2013, a raíz de los enfrentamientos en varias ciudades entre policía y manifestantes, el ministro de Defensa, Juan Carlos Pinzón, Ilamó a estos últimos como "vándalos" (El Espectador, 2013g). Posteriormente, también afirmaría que sus acciones eran producto de la infiltración de las FARC (León, 2013). Desde el inicio de la Minga de 2016 hubo declaraciones de funcionarios públicos que vincularon la protesta con supuestos intereses del ELN. El primero de junio el ministro de Defensa, Luis Carlos Villegas, afirmó que la protesta estaba infiltrada por esa guerrilla con el objetivo de presionar el inicio de los diálogos de paz (El Espectador, 2016h).

Ramírez (2001) ha demostrado que en tales declaraciones hay un sesgo paternalista sobre los campesinos, que supone que no pueden movilizarse por su propia cuenta, sino que lo hacen solamente utilizados u obligados por actores externos como la guerrilla. Estos señalamientos legitiman el uso desmedido de la fuerza en las protestas. La represión alcanzó tal nivel que varias organizaciones defensoras de los derechos humanos, encabezadas por el Movimiento de Víctimas de Crímenes de Estado y la Coordinación Colombia-Europa-Estados Unidos, solicitaron una audiencia sobre el tema a la Comisión Interamericana de Derechos Humanos, que se realizó en el marco de su periodo de sesiones 139. El informe presentado ante dicha instancia muestra unas cifras globales del período de protestas, entre el 11 de junio y el 7 de septiembre de 2013, correspondientes al paro en el Catatumbo y el paro nacional agrario, recopiladas 
con la participación de organizaciones defensoras de derechos humanos y de organizaciones de movimientos sociales, según las cuales:

902 personas fueron víctimas de algún tipo de agresión. Del total de los casos, 15 personas fueron asesinadas, 7 víctimas de algún tipo de acto cruel o tortura, entre ellos un abuso sexual; 315 personas detenidas arbitrariamente, 40 personas víctimas de fuertes golpizas, 329 que a causa de los ataques, resultaron con algún tipo de lesión y/o herida y 5 personas con heridas graves que les derivó incapacidad parcial o total. Es de resaltar que en $70 \%$ de los casos, las agresiones estuvieron acompañadas por otros tipos de violaciones... existen al menos 3 casos de presuntas desapariciones forzadas (MoviceCCEEU, 2013, p. 23).

Más allá de las cifras, tras una semana en el paro agrario de 2013, en las redes sociales virtuales empezaron a hacerse virales videos en los que aparecían agentes de Policía abusando de su fuerza en contra de manifestantes indefensos, personas de la tercera edad, niños y mujeres embarazadas; haciendo un uso inadecuado de las armas de "letalidad reducida" —al disparar a quemarropa los gases lacrimógenos, hacerlo en lugares cerrados o usar indiscriminadamente las pistolas eléctricas-, ingresando a las viviendas de los campesinos sin orden judicial para generar destrozos o hurtando las provisiones de los campesinos en protesta (Semana, 2013b).

En la Minga 2016 el Gobierno también implementó una dura represión. El 6 de junio, a los tres indígenas asesinados en el Cauca se habían sumado 162 personas detenidas arbitrariamente, 179 heridos y varios amenazados (Desde Abajo, 2016b). La Cumbre denunció que había amenazas por parte del grupo paramilitar Águilas Negras a líderes de la protesta (Colombia Informa, 2016a) y el 7 de junio solicitó medidas cautelares ante la CIDH (El Espectador, 2016i).

Ahora bien, la magnitud de las protestas campesinas, a pesar de la represión y la criminalización, puede comprenderse por la diversidad de aliados sociales y políticos que el campesinado logró articular. El paro cafetero concitó un apoyo amplio, donde convergieron actores tan diversos como el senador del Polo Democrático Jorge Robledo, el expresidente Uribe y las FARC (Semana, 2013c).
Con excepción de los actores de derecha, apoyos similares se registraron en el paro del Catatumbo. Tanto el alcalde de Tibú, Gustavo León, como el gobernador de Norte de Santander, Édgar Arias, estuvieron cercanos a las demandas del campesinado. El 28 de junio, las Comisiones de paz del Congreso de la República emitieron un comunicado instando a entablar el diálogo (Marcha Patriótica, 2013). El 22 de julio, monseñor Leonardo Gómez Serna, quien se había desempeñado como obispo en la región del Catatumbo, declaró que las demandas del campesinado eran justas y negó que las ZRC fuesen usadas por la insurgencia (Semana, 2013d).

En el paro nacional agrario de 2013 cabe resaltar el apoyo excepcional de los pobladores urbanos. En este fenómeno incidió la equivocación del presidente Santos, al tratar de reducir la magnitud de la protesta declarando que no existía. Pero, sobre todo, fue producto de la importancia que han tomado las nuevas tecnologías de la información y la comunicación en el mundo rural colombiano, puesto que las convocatorias a los cacerolazos en las ciudades y la difusión de los abusos policiales se hicieron por redes sociales virtuales. No obstante, también hubo diversas manifestaciones de apoyo de actores sociales y políticos organizados, como los que apoyaron las movilizaciones cafeteras y en el Catatumbo.

En fin, la Minga de 2016 recibió un gran respaldo por parte de diversos actores sociales y políticos. El 4 de junio un grupo de congresistas de distintos partidos, entre los que se encontraban Alirio Uribe, Ángela María Robledo, Víctor Correa, Iván Cepeda, Alberto Castilla, Jorge Enrique Robledo, Luis Évelis Andrade, Óscar Ospina, Inti Asprilla y Alexánder López, envió una carta al presidente Santos reclamando acciones urgentes para evitar la violación de derechos humanos, garantías para la protesta, que se instalara urgentemente una mesa de negociación, se investigaran los excesos de fuerza del Ejército y la Policía, y que se retractara por la vinculación entre la protesta de la Cumbre Agraria y el ELN hecha por el ministro de Defensa (Colombia Informa, 2016b). Más tarde, Amnistía Internacional (2016) instó a las autoridades colombianas a abstenerse de hacer uso excesivo de la fuerza para contener la protesta. El 8 de junio la Oficina del Alto Comisionado para los Derechos Humanos de la ONU en Colombia, como lo informa Contagio Radio (2016), también emitió un comunicado llamando, entre otras cosas, a no estigmatizar a los manifestantes de la Minga. 


\section{CONCLUSIONES}

Entre el paro nacional agrario de 2011 y la Minga Campesina, Étnica y Popular de 2016 es posible constatar una recomposición del movimiento campesino en Colombia, que se expresa en la renovada capacidad para producir grandes movilizaciones, estructuras de movilización unitarias y marcos de acción colectiva que interpelan y articulan otros sectores de la sociedad. Así, el movimiento campesino parece dejar atrás el declive que lo caracterizó una década atrás, cuando sus principales demandas revestían un carácter defensivo frente a la agudización del conflicto armado y la represión.

Este fenómeno se explica tanto por la crisis agraria que se extiende tanto en regiones con asentamientos de pequeños y medianos productores, como en aquellas de colonización reciente, ampliamente afectadas por la violencia y el marginamiento de los servicios estatales. Pero no solo la crisis del campo afecta en la generación de ese excepcional ciclo de protestas y de la recomposición organizativa y discursiva del movimiento. También el contexto político tiene una incidencia considerable, especialmente la ampliación de las oportunidades políticas para la protesta durante el Gobierno Santos, en buena parte gracias a la apertura de la agenda pública que han implicado las negociaciones de paz en La Habana y la división de las élites entre los sectores afines al presidente Santos y aquellos que apoyan al expresidente y actual senador Álvaro Uribe. Además, las movilizaciones campesinas se insertan en un ciclo de protestas más amplio que, al evidenciar la vulnerabilidad del actual Gobierno frente a este tipo de repertorio, puede alentar a diversos actores a usarlo.
De fondo, el ciclo de protesta ha significado un reencuentro, un tanto a la fuerza, de la sociedad colombiana con el campesinado. Un conjunto diverso de sujetos que, como lo muestra el recurso a instrumentos como las redes sociales virtuales para facilitar la comunicación durante las protestas, ha tenido que acoplarse a las exigencias del mundo contemporáneo y se niega a desaparecer. En este proceso la identidad del campesinado ha sufrido una importante reconfiguración, que pasa entre otras cosas por la vinculación entre los horizontes y propuestas de los distintos sectores populares rurales, los pueblos y comunidades indígenas y afrodescendientes, pero también los pequeños y medianos productores, entre otros.

Gracias a la unidad organizativa que ha conseguido en el marco de la Cumbre Agraria y de su pliego de exigencias, las reivindicaciones del movimiento hoy son proactivas y comprenden los problemas de los sectores populares rurales en términos amplios, más allá de sus reivindicaciones tradicionales, proyectando sus propuestas hacia la transformación en el modelo de desarrollo económico y la construcción de la paz.

El Gobierno Santos consiguió dilatar tanto los acuerdos con el movimiento campesino, como la discusión e implementación de sus propuestas más ambiciosas, que implican un cambio en el modelo de desarrollo rural centrado en la gran empresa y la formulación de una política agraria integral. Sin embargo, la formación de nuevos liderazgos que la recomposición del movimiento ha llevado consigo, así como su empeño por adoptar un papel propositivo y protagónico en la construcción de paz, permiten inferir que tendrá un papel de primera línea en el futuro inmediato. 


\section{REFERENCIAS}

Amnistía Internacional. (2016, 6 de junio). Amnistía Internacional. Declaración Pública. Recuperado de https://www.amnesty.org/en/documents/ amr23/4204/2016/es/

Arango, O. (2013). Del paro a la constituyente cafetera. Seminario Virtual Caja de Herramientas. Recuperado de http://www.viva.org.co/cajavirtual/svc0342/articulo04.html

Cinep. (2013). Luchas sociales, derechos humanos y representación política del campesinado 1988-2012. Bogotá: Cinep.

Colombia Informa. (2016a, 4 de junio). Denuncian grave situación de derechos humanos en el Paro Nacional. Recuperado de http://www.colombiainforma.info/ denuncian-grave-situacion-de-derechoshumanos-en-el-paro-nacional/

Colombia Informa. (2016b, 4 de junio). Bloqueos, solidaridad de congresistas y marchas en todo el país por Paro Nacional. Recuperado de http://www.colombiainforma.info/ bloqueos-solidaridad-de-congresistas-ymarchas-en-todo-el-pais-por-paro-nacional/

Congreso de los Pueblos (2016, 22 de mayo). Llamamiento al pueblo colombiano. Recuperado de http://congresodelospueblos.org/ ejes-y-sectores-vista/paro-nacional-2016/ item/884-minga-nacional-agraria-campesinaetnica-y-popular.html

Congreso de los Pueblos. (2013). Pliego Agrario y Mineroenergético: hacia un país con paz y vida digna. Recuperado de http://congresodelospueblos. org/item/543-pliego-agrario-y-minero-energetico-hacia-un-pais-con-paz-y-vida-digna.html

Congreso de los Pueblos. (2015, 31 de noviembre). Carta de la Cumbre Agraria, Campesina, Étnica y Popular al presidente Santos. Recuperado de http://congresodelospueblos. org/ser-con-otros-vista/cumbre-agraria/ item/800-carta-de-la-cumbre-agraria-campesina-etnica-y-popular-al-presidente-juanmanuel-santos.html
Contagio Radio. (2016, 8 de junio). ONU pide no estigmatizar a comunidades movilizadas en paro nacional. Recuperado de http://www. contagioradio.com/onu-llamo-a-no-estigmatizar-a-comunidades-movilizadas-en-paronacional-articulo-25140/

Cruz, E. (2014). Dignidad en movimiento. El ascenso de la movilización social en Colombia. Confluenze. Revista di Studi Iberoamericani Universitá di Bologna, 6(25), pp. 241-275.

Desde Abajo. (2016a, 1 de junio). Minga Nacional Agraria exige trato político y no militar y represivo. Recuperado de http://www.desdeabajo.info/ colombia/item/28922-minga-nacional-agrariaexige-trato-politico-y-no-militar-y-represivo. html

Desde Abajo. (2016b, 6 de junio). Algunas lecciones de 6 días de Minga. Recuperado de http:// www.desdeabajo.info/index.php

Diario del Huila. (2013, 6 de marzo). Fiscalía abrió investigación a 70 personas por desórdenes durante paro cafetero. Recuperado de http://www.diariodelhuila.com/site/index. php/menu-actualidad/32923-fiscalia-abrioinvestigacion-a-70-personas-por-desordenesdurante-paro-cafetero-

Dorado, F. (2013). Las complejidades del Paro Nacional Agrario. Recuperado de http://www.rebelion. org/noticia.php?id=172647\&titular=las-complejidades-del-paro-nacional-agrario-

Duzán, M. (2014). Emputados. El libro de los indignados colombianos. Bogotá: Planeta.

El Espectador. (2013a, 27 de febrero). Bloqueos en algunas vías afectaron abastecimiento de alimentos. Recuperado de http://www. elespectador.com/noticias/economia/ articulo-407323-bloqueos-algunas-viasafectaron-abastecimiento-de-alimentos

El Espectador. (2013b, 7 de marzo de 2013). Gobierno estableció subsidio de \$145.000. Recuperado de http://www.elespectador.com/noticias/ economia/articulo-409045-acuerdo-cafeteros

El Espectador. (2013c, 31 de julio). Logran acuerdo para desbloquear vías en Catatumbo. 
Recuperado de http://www.elespectador. com/noticias/nacional/logran-acuerdo-desbloquear-vias-catatumbo-articulo-437266

El Espectador. (2013d, 25 de agosto). El paro está bajo control y los problemas se están solucionando: Santos. Recuperado de http:// www.elespectador.com/noticias/politica/ el-paro-esta-bajo-control-y-los-problemasse-estan-solu-articulo-442317

El Espectador. (2013e, 22 de agosto). Video revela excesos de la policía en paro agrario. Recuperado de http://www.elespectador.com/ noticias/nacional/video-revela-excesos-depolicia-paro-agrario-articulo-441790

El Espectador. (2013f, 26 de febrero). Las FARC se incorporaron al paro cafetero: Minagricultura. Recuperado de http://www.elespectador. com/noticias/judicial/articulo-406902-farc-seincorporaron-al-paro-cafetero-minagricultura

El Espectador. (2013g, 29 de agosto). Presencia militar se va a incrementar en algunas ciudades: Mindefensa. Recuperado de http:// www.elespectador.com/noticias/nacional/ presencia-militar-se-va-incrementar-algunasciudades-mi-articulo-443318

El Espectador. (2016h, 6 de junio). ELN busca presionar inicio de diálogos de paz con actos violentos en paro agrario. Recuperado de http:// www.elespectador.com/noticias/nacional/ eln-busca-presionar-inicio-de-dialogos-depaz-actos-vio-articulo-636286

El Espectador. (2016i, 7 de junio). Cumbre Agraria solicita medidas cautelares a CIDH por atropellos durante paro agrario. Recuperado de http:// www.elespectador.com/noticias/judicial/ cumbre-agraria-solicita-medidas-cautelarescidh-atropel-articulo-636378

El Tiempo. (2013a, 30 de agosto). Jornada de disturbios dejó cuatro muertos en el país. Recuperado de http://www.eltiempo.com/archivo/documento/CMS-13034984

El Tiempo. (2013b, 30 de agosto). Intenciones de promotores de paro quedaron en evidencia: Vargas
Lleras. Recuperado de http://www.eltiempo. com/archivo/documento/CMS-13035579

El Tiempo. (2013c, 4 de marzo). Gobierno teme que grupos ilegales y grandes productores del grano estén manipulando a cafeteros. Recuperado de http://www.eltiempo.com/ politica/ARTICULO-WEB-NEW_NOTA_INTERIOR-12636942.htmIMinistros buscan diálogo directo con cafeteros en regiones

El Tiempo. (2013d, 16 de agosto). Esperan que marcha de agricultores y ganaderos no altere orden público. Recuperado de http://www.eltiempo. com/archivo/documento/CMS-12998014

El Tiempo. (2013e, 20 de junio). Marchas en el Catatumbo están infiltradas por las FARC: Gobierno. Recuperado de: http://www.eltiempo.com/ archivo/documento/CMS-12882977

Gamson, W. y Meyer, D. (1999). "Marcos interpretativos de la oportunidad política". En: McAdam, D., McCarthy, J. y Zald, M. (ed.), Movimientos sociales: perspectivas comparadas (pp. 389412). Madrid: Itsmo.

Godás i Pérez, X. (2007). Política del disenso. Barcelona: Icaria.

Gutiérrez, L. (2013, 26 de febrero). El porqué del paro cívico cafetero nacional. Recuperado de http:// www.nasaacin.org/noticias/3-newsflash/5377el-porque-del-paro-civico-cafetero-nacionallaura-gutierrez-escobar-

León, J. (2013). El paro, el fracaso del equipo político de Santos. Recuperado de http://lasillavacia. com/historia/el-paro-el-fracaso-del-equipopolitico-de-santos-45512

López, F. (2014). Las ficciones del poder. Bogotá: Universidad Nacional-Debate.

Marcha Patriótica. (2013, 28 de junio). Comunicado de las comisiones de paz del Congreso de la República sobre la situación en el Catatumbo. Recuperado de: http://www.marchapatriotica.org/index.php?option=com_co ntent \&view =article \&id=782: comunica do-de-las-comisiones-de-paz-del-congresode-la-republica-sobre-la-situacion-en-elcatatumbo\&catid $=107 \&$ Itemid $=482$ 
McAdam, D. (1999). Orígenes terminológicos, problemas actuales, futuras líneas de investigación. En McAdam, D., McCarthy, J. y Zald., M. (ed.), Movimientos sociales: perspectivas comparadas. Madrid: Itsmo.

McAdam, D., McCarthy, J. y Zald, M. (1999). Movimientos sociales: perspectivas comparadas. Madrid: Itsmo.

McAdam, D., Tarrow, S. y T. Ch. (2005). Dinámica de la contienda política. Barcelona: Hacer.

McCarthy, D. (1999). "Adoptar, adaptar e inventar límites y oportunidades". En: McAdam, D., McCarthy, J. y Zald, M. (eds.), Movimientos sociales: perspectivas comparadas (pp. 205220). Madrid, Itsmo.

Melucci, A. (1999). Acción colectiva, vida cotidiana y democracia. México: El Colegio de México.

Mesa Nacional Agropecuaria y Popular de Interlocución y Acuerdo -MIA-. (2015). Del paro nacional agrario a la cumbre agraria, campesina, étnica y popular. Bogotá: MIA.

Mesa Nacional Agropecuaria y Popular de Interlocución y Acuerdo -MIA-. (2013). Pliego de peticiones del paro nacional agrario y popular. Recuperado de http://prensarural.org/spip/ spip.php?article11620

Molano Bravo, A. (2013). Dignidad campesina. Entre la realidad y la esperanza. Bogotá: Ícono.

Movimiento Nacional de Víctimas de Crímenes de Estado-Coordinación Colombia Europa Estados Unidos. (2013). Informe sobre protesta social y derechos humanos. Bogotá.

Múnera, L. (1998). Rupturas y continuidades. Poder y movimiento popular en Colombia 1968-1988. Bogotá: Universidad Nacional-Cerec.

Nasaacin (2013, 1 de agosto). El 19 de agosto todos a la movilización nacional cafetera y agropecuaria. Recuperado de http://www. nasacin.org/index.php/informativonasaacin/3-newsflash/5992-el-19-de-agostotodos-a-la-movilizacion-nacional-cafetera-yagropecuaria

Olson, M. (1992). La lógica de la acción colectiva. En: Batlle, Albert (ed.), Diez textos básicos de ciencia política (pp. 203-220). Barcelona: Ariel.
PNUD. (2012). El campesinado. Reconocimiento para construir país. Bogotá: PNUD.

PNUD. (2014). Catatumbo. Análisis de Conflictividades y construcción de paz. Bogotá: PNUD.

Prada, E. (2003). "La protesta en el campo colombiano. De la lucha por la tierra a la defensa de los derechos humanos 1990-2003", Osal, 4(11), mayo agosto, pp. 53-64.

Prensa Rural. (2013, 19 de agosto). Continúa el Paro Nacional Agrario, en rechazo a las políticas neoliberales. Recuperado de: http://prensarural.org/spip/spip.php?article11742

Prensa Rural. (2016a, 29 de mayo). Ascamcat no participará del paro de la Cumbre Agraria del 30 de mayo. Recuperado de http://prensarural. org/spip/spip.php?article19457

Prensa Rural. (2016b, 11 de abril de 2014). Pliego de exigencias de la Cumbre Agraria. Recuperado de http://prensarural.org/spip/spip. php?article13670

Ramírez, M. (2001). Entre el Estado y la guerrilla: identidad y ciudadanía en el movimiento de los campesinos cocaleros del Putumayo. Bogotá: ICANH.

Restrepo, A. (2013). "Protestas en el Catatumbo: ¿y la historia?". Cien Días, 79, julio-agosto, pp. 17-20.

Rivas, A. (1998). "El análisis de los marcos: una metodología para el estudio de los movimientos sociales". En: Ibarra, p. y Tejerina, B. (eds.), Los movimientos sociales. Transformaciones políticas y cambio cultural (pp. 181-215). Madrid: Trotta.

Ruch, D. (1999). "El impacto de los contextos nacionales sobre la estructura de los movimientos sociales: un estudio comparado transnacional y entre movimientos". En: McAdam, D., McCarthy, J. y Zald., M. (ed.), Movimientos sociales: perspectivas comparadas (pp. 262287). Madrid: Itsmo.

Salcedo, L., Pinzón, R. y Duarte, C. (2013). El paro nacional agrario: un análisis de los actores agrarios y los procesos organizativos del campesinado colombiano. Inédito. 
Semana. (2013a, 30 de agosto). Santos ordena la militarización de Bogotá. Recuperado de http:// www.semana.com/nacion/articulo/santosordena-militarizacion-bogota/355743-3

Semana. (2013b, 23 de agosto). Golpiza del Esmad a un campesino. Recuperado de http://www. semana.com/nacion/articulo/la-golpiza-delesmad-campesino-video/355013-3

Semana. (2013c, 27 de febrero). Uribe y 'Márquez', 'unidos' en apoyo al paro cafetero. Recuperado de http://www.semana.com/nacion/ articulo/uribe-marquez-unidos-apoyo-parocafetero/334844-3

Semana. (2013d). Protestas en el Catatumbo son justas. Recuperado de http://www.semana. com/nacion/articulo/protestas-catatumbojustas/351752-3

Semana. (2016, 16 de marzo). ¿Campesinos convocarán a otro paro agrario? Recuperado de http://www.semana.com/nacion/articulo/ campesinos-indigenas-debaten-sobre-paztierras-mineria/380743-3

Smelser, N. (1995). Teoría del comportamiento colectivo. México: FCE.

Snow, D. y Benford, R. (1992). "Master frames and cycles of protest". En: Morris, A. y McClury,
C. (eds.), Frontiers in social movement theory (pp. 133-155). New Haven and London: Yale University Press.

Suhner, S. (2002). Resistiendo al olvido. Bogotá: Taurus UNRISD.

Tarrow, S. (1997). El poder en movimiento. Madrid: Alianza.

Touraine, A. (1987). El Regreso del actor. Buenos Aires: Eudeba.

Vélez, J. (2016, 31 de mayo). Sin las Dignidades el paro agrario no es lo mismo (por ahora). Recuperado de http://lasillavacia.com/historia/ sin-las-dignidades-el-paro-agrario-no-es-lomismo-por-ahora-56025

Wallerstein, I. (2008). Historia y dilemas de los movimientos antisistémicos. Bogotá: Desde Abajo.

Zald, M. (1999). "Cultura, ideología y creación de marcos estratégicos". En: McAdam, D. McCarthy, J. y Zald, M. (eds.), Movimientos sociales: perspectivas comparadas (pp. 369388). Madrid: Itsmo.

Zibechi, R. (2006). Dispersar el poder. Buenos Aires: Tinta Limón. 